Mathematical Modelling and Analysis

Volume 6 Number 2, 2001, pages 167-177

(C) 2001 Technika

\title{
NUMERICAL INVESTIGATION OF MOISTURE MOVEMENT IN WOOD UNDER ISOTHERMAL CONDITIONS ${ }^{1}$
}

\author{
R. BARONAS ${ }^{1}$, F. IVANAUSKAS ${ }^{1,2}$, M. SAPAGOVAS ${ }^{2}$ \\ ${ }^{1}$ Vilnius University \\ Naugarduko 24, 2006 Vilnius \\ ${ }^{2}$ Institute of Mathematics and Informatics \\ Akademijos 4, 2600 Vilnius \\ E-mail: romas.baronas@maf .vu. It
}

Received September 30, 2001; revised November 7, 2001

\begin{abstract}
The present work summarizes the results of several previous studies on moisture movement in wood during drying under isothermal conditions. A model of the wood drying taking into consideration coating of the surface of a specimen is presented in three-dimensional-in-space (3-D) formulation. The influence of the geometrical shape as well as surface coating degree of wood specimens from the northern red oak (Quercus rubra) on the drying dynamics is investigated. The conditions of usage of 2-D moisture transfer model in contrast to 1-D for accurate predicting of the drying process are described.
\end{abstract}

\section{INTRODUCTION}

Trees contain a considerable amount of water. Most water in the cut tree must be evaporated before useful products can be made from wood. The reason for drying lumber is to increase the strength and rigidity as well as to protect the wood against biological damage. There are also some negative aspects to drying wood, including the great amount of energy that must be expended to drive the water out of wood, and the possibility of drying defects. Understanding the fundamental concepts that underly lumber drying can guide

\footnotetext{
${ }^{1}$ This work was partially supported by Lithuanian State Science and Studies foundation Grant Nr. A-524.
} 
the selection of economical and efficient drying methods that result in high quality products.

The water or moisture content (MC) of wood is expressed, in percent, as the weight of water present in the wood divided by the weight of dry woodsubstance. Wood drying is usually accomplished by evaporating the moisture from the surface of wood. When the surface moisture evaporates from the sides or ends, moisture moves from interior toward these locations. This process continues until the wood reaches its equilibrium moisture content (EMC) with the ambient air climate.

From the mathematical point of view moisture transport process in wood, under isothermal conditions, can be described by the diffusion equation with the initial and boundary conditions. The initial condition expresses an initial moisture concentration in the specimen, and the boundary condition describes the surface evaporation $[11 ; 12 ; 15 ; 18]$.

In the literature 1-D-in-space moisture transfer models have been widely used in various investigations. 1-D model describes the wood drying process accurately for extremely long and wide plates. However, 1-D analysis can be successfully used to predict the drying process for a relatively short and narrow specimen if four of six surfaces are heavily coated in order to reduce the moisture transfer from those four surfaces.

The advantage of 1-D moisture transfer model is an efficiency of the problem solution. Because of this, it is important to estimate a level (degree) of surface coating, making 1-D model as admissible to predict the wood drying process accurately.

Several authors have used a wood drying model to solve the inverse coefficient problem $[9 ; 10 ; 18 ; 20]$. The inverse solutions are known to be sensitive to changes in input data resulting from measurement and modelling errors [19]. Hence, they may not be unique. Nevertheless, the determination of the diffusion as well as surface emission coefficients for various species of wood is the problem of today $[5 ; 6 ; 10 ; 13 ; 20]$. Since the multidimensional inverse methods are especially complex, it is important to estimate a reliability of 1-D-in-space model to predict the drying process accurately.

The present work summarizes the results of previous studies $[1 ; 2 ; 3 ; 4]$. The conditions of usage of 2-D moisture transfer model in contrast to 1-D for accurate predicting of the drying process are analyzed in this work. A measure of reliability of 1-D model to predict the wood drying process of sawn boards has been introduced. The influence of the specimen surface coating on the drying dynamics is investigated in a relation to the geometry of the specimen. The dependence of the half-drying time on the ratio of the width to the thickness of the transverse section of sawn boards from the northern red oak (Quercus rubra) was investigated for different degrees of edges coating. 


\section{MOISTURE MOVEMENT MODEL}

In a 3-D-in-space formulation, the moisture movement, under isothermal conditions, in a symmetric wood piece of thickness $2 a$, width $2 b$ and length $2 c$ can be expressed through the following equation of diffusion type:

$$
\begin{aligned}
& \frac{\partial u}{\partial t}=\frac{\partial}{\partial x}\left(D_{1}(u) \frac{\partial u}{\partial x}\right)+\frac{\partial}{\partial y}\left(D_{2}(u) \frac{\partial u}{\partial y}\right)+\frac{\partial}{\partial z}\left(D_{3}(u) \frac{\partial u}{\partial z}\right), \\
& x \in(0, a), y \in(0, b), z \in(0, c), t \in(0, T]
\end{aligned}
$$

here $u=u(x, y, z, t)$ is moisture content, $t$ is time, and $D_{1}(u), D_{2}(u), D_{3}(u)$ are the moisture concentration-dependent diffusion coefficients in the space directions $x, y, z$, respectively. The initial condition $(t=0)$ is

$$
u(x, y, z, 0)=u_{0}, \quad x \in[0, a], y \in[0, b], z \in[0, c] .
$$

Let us assume, that each side of a sawn board may be coated, e.g. painted, to reduce moisture transfer from the surface. Let coating of opposite sides be identical. The boundary conditions that describe symmetry and surface evaporation $(t>0)$ are

$$
\begin{array}{r}
\left.\frac{\partial u}{\partial x}\right|_{x=a}=\left.\frac{\partial u}{\partial y}\right|_{y=b}=\left.\frac{\partial u}{\partial z}\right|_{z=c}=0, \\
-D_{1}(u) \frac{\partial u}{\partial x}=\left(1-\alpha_{1}\right)\left(S u_{e}-u\right), \quad x=0 \\
-D_{2}(u) \frac{\partial u}{\partial y}=\left(1-\alpha_{2}\right)\left(S u_{e}-u\right), \quad y=0 \\
-D_{3}(u) \frac{\partial u}{\partial z}=\left(1-\alpha_{3}\right)\left(S u_{e}-u\right), \quad z=0,
\end{array}
$$

where $S$ is the surface emission coefficient, $u_{e}$ is the equilibrium moisture content (EMC), and $\alpha_{i}$ is dimensionless degree of surface coating, $0 \leq \alpha_{i} \leq$ $1, i=1,2,3$. Let us notice, if a side of a board is extremely coated, then corresponding surface coating degree is 1 , and it equals to 0 if the surface is not coated at all.

Though the radial and tangential diffusion coefficient may be different, it was assumed that the transverse diffusion coefficient $D(u)$ is the same in both space directions $x$ and $y$. It was also assumed that the longitudinal diffusion in wood is faster than the transverse one [15]:

$$
D_{1}(u)=D_{2}(u)=D(u), \quad D_{3}(u)=K D(u),
$$

where $K$ is an experimentally determined coefficient $(K>1)$. 
The next assumption was that the diffusion function $D(u)$ is constant above the fiber saturation point (fsp) (the moisture content at which only the cell walls are completely saturated but no water exists in cell lumens) and it is equal to the diffusion coefficient at the fsp value:

$$
D(u)= \begin{cases}f(u), & u \leq u_{f s p} \\ f\left(u_{f s p}\right), & u>u_{f s p}\end{cases}
$$

where $u_{f s p}$ denotes the fsp (fsp is about 30\%) and function $f$ expresses the diffusion coefficient in moisture content, and temperature:

$$
f(u)=A e^{B / T+C u},
$$

where $T$ is the temperature in Kelvin, A, B, C are experimentally determined coefficients $[7 ; 15 ; 16]$.

\section{SOLUTION AND VERIFICATION OF THE MODEL}

Analytical solutions of problems, described by partial differential equations of the diffusion type, do not usually exist in cases of variable diffusion coefficients and complex boundary conditions. Therefore the mathematical model represented was solved numerically. The finite-difference technique has been used for the discretization of the model [14]. We introduced a non-uniform discrete grid to increase the efficiency of calculations. Since moisture evaporates from the surface of a piece of wet wood, an exponentially increasing (bi-linear) step of the grid was used in all space directions from the surface of the wood piece to the center, while a constant step was used in time direction. The explicit difference scheme for the model (2.1)-(2.4) has been designed and realized to simulate the moisture movement in the wood specimen [1].

The average moisture content is usually measured at various time to predict the dynamics of drying in a physical experiment. The calculated average moisture content $\bar{u}(t)$ values at any time $t$ were determined by numerical integration of the finite difference solutions. The relative amount of the remaining moisture content in wood during drying at time $t$ is usually called as the fraction of total moisture content [15], and can be defined as

$$
E(t)=\left(\bar{u}(t)-u_{e}\right) /\left(u_{0}-u_{e}\right) .
$$

Let $t_{0.5}$ be the time when the drying process reaches the medium, called half-drying time, i.e. $E\left(t_{0.5}\right)=0.5$. The half-drying time was employed to investigate the dynamics of the drying process.

In the calculations, discussed below, a corresponding model in 1-D and 2$\mathrm{D}$ formulation was also used. The model in 1-D and 2-D formulation can be rather easily derived from the model (2.1)-(2.4) by ignoring the corresponding space coordinates. 
The moisture transfer model (2.1)-(2.4) was employed for computer simulation of the drying of specimens from northern red oak. The experimental moisture content values for red oak by Simpson and Liu [17] were used for numerical analysis. Experimental drying conditions were $43^{\circ} \mathrm{C}$ at $84 \%$ relative humidity (EMC $u_{e}=16.2 \%$ ). There were two air velocities: 1.5 and 5.1 $\mathrm{m} / \mathrm{s}$. The size of specimen was 102 by 305 by $29 \mathrm{~mm}$, i.e., $2 a=29,2 b=102$, $2 c=305$. The average initial moisture content $u_{0}$ was $82.5 \%$. Values of the coefficients $A, B, C$ in (2.7) and $S$ in (2.4) were found [17] for both air velocities.

In the physical experiment four of six surfaces were heavily coated in order to reduce the moisture transfer from those four surfaces, while the edges of the specimen were not coated absolutely. Because of this the model in 1-D-inspace formulation was used to simulate the drying process assuming $\alpha_{1}=0$. The good agreement between the finite difference solution of the drying problem and experimental data was obtained. The calculated average moisture content values compared also favorably with the results of Simpson and Liu [17] determined using 1-D-in-space drying model. The result of calculation showed that the half-drying time $t_{0.5}$ equals to $113.6 \mathrm{~h}$ at air velocity $1.5 \mathrm{~m} / \mathrm{s}$ and $87.7 \mathrm{~h}$ at air velocity $5.1 \mathrm{~m} / \mathrm{s}$.

The physical experiment was also simulated using this model in 2-D-inspace formulation. Because edges of specimen were heavily insulated, it was assumed that $\alpha_{2}=1$. The differences between results of calculation did not exceed the error of calculations, e.g. values of $t_{0.5}$ were the same as above.

\section{THE INFLUENCE OF SURFACE COATING ON MOISTURE MOVEMENT}

We have investigated the influence of the surface coating degree as well as geometry of the transverse section of a specimen on drying dynamics assuming that the specimen is extremely long or ends are extremely coated. The wide surfaces of the specimen were assumed to be not coated as it was in the physical experiment, i.e. $\alpha_{1}=0$. Let $\alpha$ be the degree of coating of edges $\left(\alpha=\alpha_{2}\right)$.

The transverse section of a specimen was modelled as a rectangle having various width keeping the thickness equal to $a=29 \mathrm{~mm}$. Since the thickness of the specimen was assumed constant while the width varied, a dimensionless ratio $k$ of the width to the thickness of the specimen, $k=(2 b) /(2 a)=b / a$, was introduced as a characteristic of the geometry of the transverse section. The problem (2.1)-(2.4) was solved numerically for various values of the ratio $k(1 \leq k \leq 100)$ and coating degree $\alpha(0 \leq \alpha \leq 1)$. In each board geometry and degree of edges coating case, the drying until the half-drying time was simulated to determine dynamics of the drying for both air velocities: 1.5 and $5.1 \mathrm{~m} / \mathrm{s}$. The results of calculations at air velocity $5.1 \mathrm{~m} / \mathrm{s}$ are depicted in Fig. 1. Fig. 1 shows the dependence of the half-drying time $t_{0.5}$ on the ratio $k$ of the width to the thickness for specimens of the thickness $29 \mathrm{~mm}$ for several 
values of the degree $\alpha$ of edges coating: $0,0.5,0.9,0.95,0.99$ in case of air velocity $1.5 \mathrm{~m} / \mathrm{s}$. Because of petty change of $t_{0.5}$ for $k>30$ the results of calculations are depicted for $k \leq 30$ only.

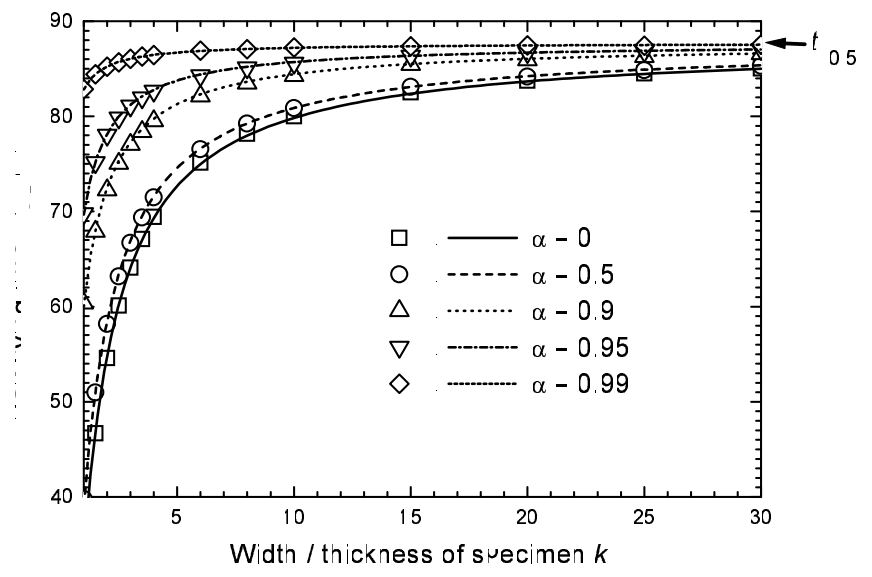

Figure 1. Dependence of half-drying time $t_{0.5}$ on the ratio $k$ of the width to the thickness of specimens of the thickness $29 \mathrm{~mm}$ at different values of coating degree $\alpha$ and air velocity $v=5.1 \mathrm{~m} / \mathrm{s}$.

Let us redefine the half-drying time $t_{0.5}(\alpha, k)$ as a function of coating degree $\alpha$ and ratio $k$. In Fig. 1, curves drawn through the calculated values of halfdrying time are

$$
t_{0.5}(\alpha, k)=t_{0.5}^{*} e^{E_{\alpha} / k}, \quad t_{0.5}^{*}=\lim _{k \rightarrow \infty} t_{0.5}(\alpha, k),
$$

where $t_{0.5}(\alpha, k)$ is the half-drying time of the specimen calculated by using 2 -D model, $t_{0.5}^{*}$ is a limiting value of half-drying time, extremely increasing the width of the specimen, and $E_{\alpha}$ is a coefficient specific for coating degree $\alpha$. Let us notice, that the value of $t_{0.5}^{*}$ does not depend on the degree $\alpha$ of edges coating. This value can also be calculated as the half-drying time of a specimen having extremely coated edges, i.e. in the case when $\alpha=\alpha_{2}=1$. This value was found equal to $87.7 \mathrm{~h}$ at air velocity $5.1 \mathrm{~m} / \mathrm{s}$ while the simulation of the physical experiment.

Function (4.1) was also fitted to the results of calculations for air velocity $1.5 \mathrm{~m} / \mathrm{s}$. Values of the coefficient $E_{\alpha}$ can be found in $[2 ; 4]$ for both air velocities.

As it is possible to notice in Fig. 1, the relative thickness of a board appears to be important for the drying dynamics at different values of the degree $\alpha$ of coating of edges. This importance decreases with increasing of $\alpha$. In the 
case of uncoated edges $(\alpha=0)$, the half-drying time notable increases with increase of the ratio $k$ up to $k \approx 10$. Very similar situation appears in the case where $\alpha=0.5$. The calculation showed that in these two cases of $\alpha(0$ and $0.5)$ values of $t_{0.5}(\alpha, k)$ varies less than $2 \%$ for $k>7$ and both air velocities. The increase of half-drying time with increase of $k$ is rather slight for greater values of $\alpha(\alpha>0.9)$.

In addition to the thickness of $2 a=29.0 \mathrm{~mm}$ of the specimen, we have calculated $t_{0.5}^{*}, t_{0.5}(\alpha, 10)$ and $t_{0.5}(\alpha, 30)(\alpha \in\{0,0.5,0.9,0.95,0.99\})$ for two thicknesses more: $58.0 \mathrm{~mm}$ and $14.5 \mathrm{~mm}$. The calculations showed that in all these cases $t_{0.5}(\alpha, 10)=(0.91 \pm 0.01) t_{0.5}^{*}$ and $t_{0.5}(\alpha, 30)=(0.97 \pm 0.005) t_{0.5}^{*}$ for both air velocities. So, the half-drying time varies only slightly for relatively wide specimens of the typical for sawn timber domain width.

In the case of use of 1-D-in-space model, the calculated half-drying time equals to $t_{0.5}^{*}$. Because of this, the use of 1-D model can be called as admissible for a board if the half-drying time, calculated by using corresponding 2-D model, equals approximately also to $t_{0.5}^{*}$.

Let us define a function $p$ of coating degree $\alpha$ and ratio $k$ as follows:

$$
p(\alpha, k)=\left(t_{0.5}^{*}-t_{0.5}(\alpha, k)\right) / t_{0.5}^{*},
$$

where $k$ is the ratio of the thickness to the width of a specimen, $t_{0.5}(\alpha, k)$ is the half-drying time of the specimen calculated by using 2-D model. The specimen was assumed as an extremely long sawn board. Since $t_{0.5}^{*}$ can be also calculated by using an appropriate 1-D model, $p(\alpha, k)$ can be called as a relative error of the use of 1-D model for a specimen having the width $k$ times greater than the thickness. $p(\alpha, k)$ may also be called as a level of 1-D model reliability to predict a drying process of a sawn board. Let us notice that $0 \leq p(\alpha, k) \leq 1$.

Using a computer simulator based on 2-D model and the definition of the relative error of the usage of 1-D model, it is possible to adjust value of $k$ as well as $\alpha$ ensuring the error not greater than the required one in case of use of the 1-D model. Let us define an inverse function $k_{\alpha}(p)$ to the function $p(\alpha, k)$ as the minimal value of the ratio $k$ for which $p(\alpha, k)$ does not exceed $p$ at given $\alpha$, i.e.

$$
k_{\alpha}(p)=\min \{k: p(\alpha, k) \leq p\} .
$$

In other words, if $k$ is the ratio of the width to the thickness of a specimen, $k \geq k_{\alpha}(p)$, and $\alpha$ is the degree of edges coating of the specimen then the relative error of the half-drying time, calculated by using 1-D model, does not exceed $p$ for this specimen due to the use of the 1-D model.

We have calculated $k_{\alpha}(p)$ for several values of $\alpha$ and $p$ [4]. It was noticed that the accurate result of the half-drying time can be achieved by using 1D model if a specimen is relatively wide, irrespective of the level of edges coating. However, the accurate result can be achieved also by increasing the 
degree of the edges coating. For example, if 1-D model is used for a specimen having $k \geq 4$ and $\alpha \geq 0.95$, then the relative error $p$ of the result will not exceed 0.05 because of use of 1-D model, i.e. relative difference between half-drying time calculated by using $2-\mathrm{D}$ model and another one calculated by using appropriate $1-\mathrm{D}$ model does not exceed 0.05 . The values of $k_{\alpha}(p)$ depend on the drying conditions slightly.

\section{THE INFLUENCE OF THE SPECIMEN GEOMETRY ON DRYING DYNAMICS}

The influence of the width of sawn boards on drying dynamics, has been analyzed above, assuming the thickness constant. The transverse section of lumber was also modelled as a rectangle changing in both directions: the width and thickness. Edges of specimens were assumed to be not coated as wide surfaces to exclude the influence of coating, i.e. $\alpha_{1}=\alpha_{2}=0$. Results of multiple numerical experiments based upon the idea that the half-drying time depends mainly on the ratio $l(\mathrm{~mm})$ of the area to the perimeter of the transverse section of the board, $l=(a b) /(a+b)$.

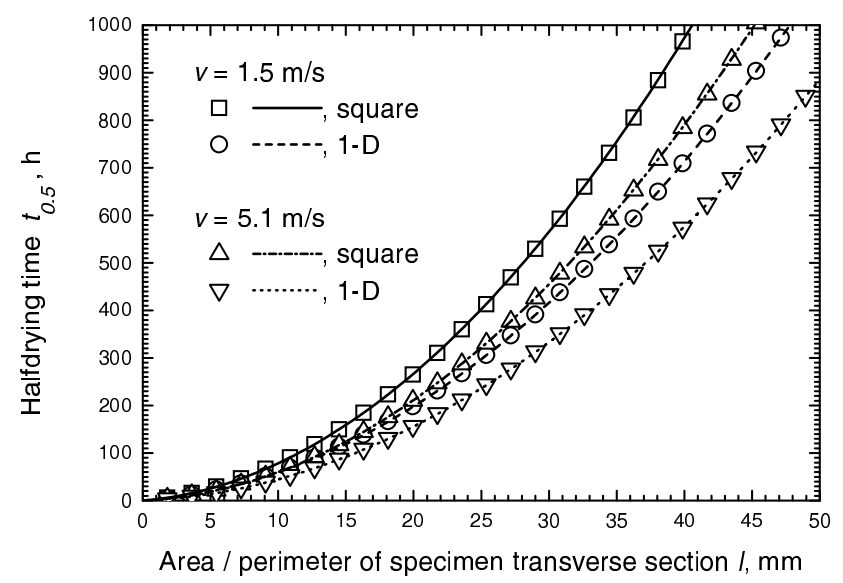

Figure 2. Dependence of half-drying time $t_{0.5}$ on the ratio $l$ of the area to the perimeter of the transverse section of specimens at two air velocities $v$ : 1.5 and $5.1 \mathrm{~m} / \mathrm{s}$.

We have investigated two extreme cases of the geometrical shape of the transverse section of the specimen:

a) a square changing the side $(l=a / 2)$,

b) an extremely wide rectangle increasing the thickness $(l \rightarrow a)$. 
The 2-D-in-space model was used in case (a) and the 1-D model was used to predict half-drying time in case (b). The results of calculations are presented in Fig. 2.

Curves drawn through the half-drying time values in all the cases are polynomials of the second order $[2 ; 3]$. The polynomial fits two extreme cases (a) and (b) form a sector for each air velocity. As it is possible to notice in Fig. 2, these two sectors intersect. Additional calculations showed that values of the half-drying time lie in this sector for any specimen being of the shape of a rectangle in the transverse section. This property is valid for both air velocities: 1.5 and $5.1 \mathrm{~m} / \mathrm{s}$.

The investigation above was extended to 3-D moisture movement. Let $m$ be the ratio of the volume to the whole surface area of the specimen $(\mathrm{mm})$, $m=(a b c) /(a b+b c+a c)$.

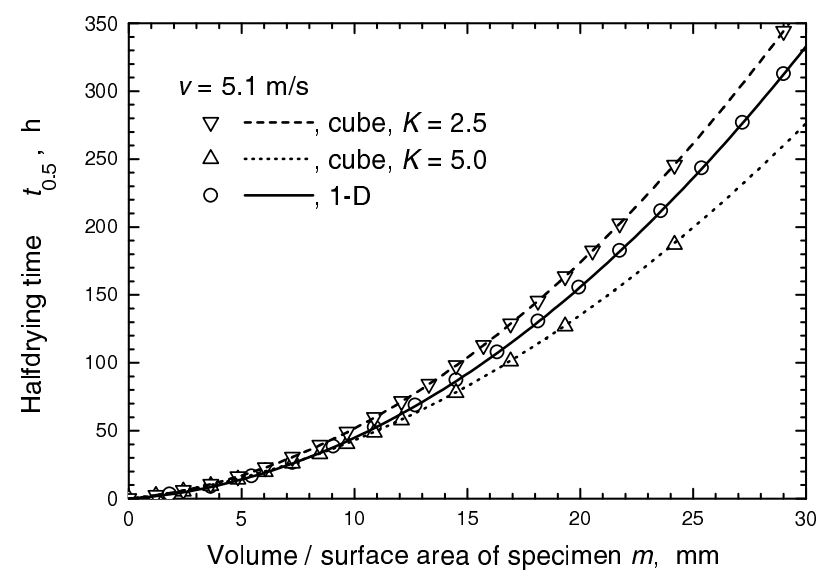

Figure 3. Dependence of half-drying time $t_{0.5}$ on the ratio $m$ of the volume to the whole surface of specimens at air velocity $v=5.1 \mathrm{~m} / \mathrm{s}$.

We investigated the influence of the ratio $m$ on half-drying time for a specimen as a rectangular parallelepiped. We chose two extreme cases:

c) a cube changing the side $(m=a / 3)$,

d) an extremely wide and long plate increasing the thickness $(m \rightarrow a)$.

The 3-D-in-space model was used to simulate drying in case (c). Case (d) is equivalent to case (b), which was discussed above. The 3-D model requires a value of the dimensionless coefficient $K$ (how many times the longitudinal diffusion is faster than the transverse one). We used two different values of that coefficient: 2.5 [15] and 5.0 [8]. The results of calculations are presented in Fig. 3 at air velocity of $5.1 \mathrm{~m} / \mathrm{s}$. The fits to values of the half-drying time 
for the cubic specimens (c) were expressed as polynomials of the second order at both air velocities [3].

The fits for cases (c) and (d) form a sector for both values of the coefficient $K: 2.5$ and 5.0, and both air velocities. We have established that values of half-drying time lie in this sector for any specimen being as a rectangular parallelepiped for both air velocities and both values of $K$, provided $c \geq a$, $c \geq b$. The last condition is important because of the assumption that the longitudinal diffusion is faster than the transverse one.

\section{CONCLUSIONS}

The 3-D-in-space moisture transfer model (2.1)-(2.4) taking into consideration the degree of coating of the surface of a wood specimen can be successfully used to investigate the influence of the surface coating degree as well as geometrical shape of the specimen of northern red oak on the drying dynamics from above the fiber saturation point under isothermal conditions.

The 2-D model guarantees better prediction of the drying process than the 1-D one if the ratio of the width to the thickness of a specimen is rather small (less than about 10) or the degree of coating of edges is not very high (less than 0.95-0.99).

The half-drying time can be expressed as an exponential of the ratio of the width to the thickness of a specimen for different values of the degree of coating of edges. The half-drying time can be expressed as the second order polynomial of the ratio of the area to the perimeter of the transverse section of the specimen for two extreme cases of the geometrical shape of the section: a square and an extremely wide rectangle. A similar pair of polynomials of the second order expresses the dependence of the half-drying time on the ratio of the volume to the whole surface of the specimens in the shape of a rectangular parallelepiped.

\section{REFERENCES}

[1] R.Baronas, F.Ivanauskas and M.Sapagovas. Modelling of wood drying and an influence of lumber geometry on drying dynamics. Nonlinear Analysis: Modelling and Control, $41999,11-22$.

[2] R.Baronas, F.Ivanauskas and M.Sapagovas. Numerical investigation of moisture movement in wood during drying. In: Proc. of the Conference FDS2000 September 1-4, 2000, Palanga, Finite Difference Schemes Theory and Applications, R. Čiegis, A.Samarskii and M.Sapagovas (Eds.), IMI, Vilnius, 2000, $11-22$.

[3] R.Baronas, F.Ivanauskas and M.Sapagovas. The influence of wood specimen geometry on moisture movement during drying. Wood and Fiber Science, 33 (2), 2001, 166 - 172.

[4] R.Baronas and F.Ivanauskas. The influence of wood specimen surface coating on moisture movement during drying. Holzforschung, (accepted).

[5] L.Cai and S. Avramidis. Study on the separation of diffusion and surface emission coefficient of wood. Drying Technol., 15 (5), 1997, 1457-1473. 
[6] A.Hukka. The effective diffusion coefficient and mass transfer coefficient of Nordic softwoods as calculated from direct drying experiments. Holzforschung, 53 (5), 1999, 534 -540 .

[7] A.J. Hunter. Equilibrium moisture content and the movement of water through wood above fiber saturation. Wood Sci. Technolog., 29, 1995, $129-135$.

[8] H. Liu. Development of a simulation model for drying deformation in radiata pine boards. Ph.D. thesis. Lincoln University, New Zealand, 1998.

[9] J.Y. Liu and W.T. Simpson. Solutions of diffusion equation with constant diffusion and surface emission coefficients. Drying Technol., 15 (10), 1997, 2459-2477.

[10] J.Y. Liu and W.T. Simpson. Inverse determination of diffusion coefficient for moisture diffusion in wood. In: Proc. of 33rd ASME National Heat Transfer Conference, Heat and Mass Transfer in Porous Media, August 15-17, 1999, Albuquerque, New Mexico, 1999.

[11] H.N. Rosen. The influence of external resistance on moisture adsorption rates in wood. Wood Fiber Sci., 10 (3), 1978, 218-228.

[12] H.N. Rosen. Recent advances in the drying of solid wood. Adv. in drying, Mujumdar (Ed.), Hemisphere, 4 , 1987, 99 - 146.

[13] A.Rosenkilde and J.Arfvidson. Measurement and evaluation of moisture transport coefficient during drying of wood. Holzforschung, 51 (4), 1997, $372-380$.

[14] A.A. Samarskii. Theory of Difference Schemes. Nauka, Moskow, 1989. (in Russian)

[15] J.F. Siau. Transport Processes in Wood. Springer-Verlag, New York, 1984.

[16] W.T. Simpson. Determination and use of moisture diffusion coefficient to characterize drying of northern red oak (Quercus rubra). Wood Sci. Technolog., 27 , 1993, $409-$ 420 .

[17] W.T. Simpson and J.Y. Liu. An optimization technique to determine red oak surface and internal moisture transfer coefficients during drying. Wood Fiber Sci., 29 (4), 1997, $312-318$.

[18] O. Söderström and J.G. Salin. On determination of surface emission factors in wood drying. Holzforschung, 47 (5), 1993, 391 - 397.

[19] A.N.Tikhonov and V.Y. Arsenin. Solutions of ill-posed problems. John Wiley, New York, 1977.

[20] J.Weres, W.Olek, R.Guzenda. Identification of mathematical model coefficients in the analysis of the heat and mass transport in wood. Drying Technol., 18 (8), 2000, 1697 -1708 .

\title{
DRE்GMĖS JUDE்JIMO MEDIENOJE IZOTERMINE்MIS SĄLY- GOMIS MODELIAVIMAS
}

\author{
R. BARONAS, F. IVANAUSKAS, M. SAPAGOVAS
}

Šiame darbe yra apžvelgiama keletas ankstesnių darbų, kuriuose buvo nagrinėjama drègmès judėjimas medienoje džiovinant ją izoterminèmis sąlygomis. Straipsnyje yra pateiktas trimatis medienos džiovinimo modelis, kuriame atsižvelgiama i galimą bandinio paviršiaus izoliavimą. Bandinio geometrinès formos bei paviršiaus izoliavimo lygmens įtaka džiūvimo dinamikai yra ištirta bandiniams, pagamintiems iš šiaurès ąžuolo (Quercus rubra). Darbe yra išanalizuotos sąlygos, nusakančios, kuomet yra tikslingiau naudoti dvimati modeli vietoje atitinkamo vienmačio modelio. 